\begin{abstract}
NiCOLÁS ETCHEVERRY ESTRÁZULAS Profesor de Filosofía del Derecho y Ética en la Facultad de Derecho de la Universidad de Montevideo (Uruguay) netcheverry@um.edu.uy ORCID ID: https://orcid.org/0000-0002-72 I 0-4090 Recibido: 13/10/2021 - Aceptado 15/1 1/2021

Para citar este artículo / To reference this article / Para citar este artigo Etcheverry Estrázulas, N. (2021). Normas, señales y autoridad - siembras y cosechas. Revista de Derecho, 20(40), I 13-127. https://doi.org/10.47274/DERUM/40.6
\end{abstract}

\title{
Normas, señales y autoridad - siembras y cosechas
}

Palabras clave: ética, normas, valores. 
Rules, signs and authority - sowing and harvesting

Keywords: ethics, norms, values.

Regras, sinais e autoridade - sementeira e colheita

Palavras-chave: ética, normas, valores. 
La importancia de las señales y los carteles en las rutas es indiscutible. Son de gran necesidad para saber cómo llegar a los diversos destinos. En las regiones nevadas, cuando la nieve cubre muchas veces a las carreteras, sobresalen cada tanto unos postes altos, habitualmente pintados de rojo, que marcan por dónde va el camino para que los transeúntes no se descarrilen. Lo mismo ocurre con las señas; deben estar orientadas y ubicadas hacia donde deben indicar la dirección y el destino, pues si se cambiara su orientación podrían confundir y provocar que los que siguen y leen esas señas no lleguen al mismo, o al menos lleguen mucho más tarde.

Todo esto viene a cuento, porque también las normas, los especialistas, los gobernantes y toda persona que ejerce cierto grado de autoridad, señalan, marcan rumbos, orientan; influyen, porque contribuyen a educar. No comparto la idea que sostiene que las leyes y las normas en general no educan, pues solamente recogen lo que de antemano se viene gestando, aceptando y viviendo en un grupo social dado. Puede haber casos y situaciones en los que efectivamente ese fenómeno se cumpla de esa manera, pero también existen muchísimos otros en los que una norma, un comportamiento, una actitud, una expresión oral o frase, e incluso una omisión, puede dar lugar a marcar un rumbo, una nueva tendencia que - con el transcurrir del tiempo - pase a ser costumbre adquirida y aceptada como normal. Las normas y el ejemplo son parientes muy próximos: se tiene por supuesto que las leyes (hablemos de normas en sentido más amplio, para no restringir los casos a las meramente jurídicas) son en general ejemplares, y se supone también que muchos ejemplos de conductas humanas pueden servir para que sean plasmadas en normas universales. Obviamente, como todos los parientes, no siempre se llevan bien y van de la mano; a veces se contradicen y pelean, de la misma forma que la justicia no siempre está aliada con las leyes vigentes en un orden social dado.

A lo que pretendo apuntar es que - en general - las normas emitidas por autoridades competentes y las conductas y actitudes de esas autoridades, sea en el campo que sea, van cristalizando ejemplos y acostumbramientos que se van arraigando cada vez más fuertemente en una sociedad.

Para ilustrar mejor mi propuesta, aquí van unos ejemplos que pueden servir como explicación de lo que quiero transmitir:

1) Ejemplo de conducta y actitud privada ante una simple norma de educación: En la sala de estar de una casa, están sentados una joven, una pareja amiga de la joven y una señora mayor, abuela de la primera joven. La televisión está encendida y la abuela está mirando un capítulo de una serie televisiva, mientras que la joven y sus amigos conversan animadamente, sin prestarle mucha atención a la telenovela. En determinado momento llega el novio de la joven, saluda a todos, incluida la abuela y toma asiento en el sofá al lado de ella, enfrente de la televisión. No pasan ni tres minutos cuando el joven se pone de pie, toma el control remoto y sin hacer ningún tipo de comentario o pregunta, cambia de canal, lo sintoniza en un partido de fútbol y vuelve a sentarse cómodamente en el sofá. La abuela mira con cierto grado de sorpresa a la novia del joven, a su pareja de amigos, y con un gesto de resignación, encoje los hombros y acepta no seguir viendo la serie que venía mirando, para ver en vez el partido de fútbol.

Alguno de ustedes se puede preguntar ¿Por qué la novia o la pareja de amigos no reaccionó y le hizo ver al joven su descortesía, desinterés y desplante ante la abuela? No 
hay una respuesta cierta y única; quizás no todos se percataron del incidente; o quienes lo notaron prefirieron no generar un incidente más desagradable por algo que podía considerarse una trivialidad; o no quisieron dejar en evidencia la desconsideración del recién llegado por otros motivos. Lo que me importa destacar en este caso, es la doble significación que tuvo en los protagonistas. A) Por parte del joven "futbolero", la falta de respeto ante una persona mayor que estaba mirando un programa televisivo, pues sin pedirle permiso o consultarle siquiera si aceptaba un cambio de programa, aunque más no fuera por unos minutos, para ver cómo iba el famoso partido de fútbol, toma el control de la TV y no solamente cambia de programa, sino que lo deja atornillado con tuerca y contratuerca por el resto del partido. B) Por el lado de la abuela, persona mayor y excesivamente "bien educada", su resignación y falta de reacción ante el desplante del joven. Eso no fue tolerancia, sino soportar un abuso; aguantar un alto grado de indiferencia y desinterés ante los gustos o necesidades ajenas. Esa claudicación, quizás para no dejarlo en evidencia, para disimular caritativamente su descortesía, corre el riesgo de transformarse en hábito, en acostumbramiento a transigir y sobrellevar cualquier conducta que debería entenderse errónea. La falta de corrección a tiempo puede ser un mal mayor para quien hace algo incorrecto, pues si nadie le hace notar su error, se acostumbrará a seguir haciéndolo.

2) Ejemplo de conducta y actitud pública ante una norma legal: Hace unos años, un Presidente de la República de nuestro país, mientras cumplía con sus años de mandato institucional, visitaba una localidad del interior del país. Lo hacía como muchas veces lo han hecho y siguieron haciéndolo nuestros mandatarios; sin mayores protocolos, ni pompa ni medidas extremas de seguridad. Simplemente pasaba muy cerca de los que quisieran verle, saludarle y hasta conversar con él. Es algo que - insisto - nos ennoblece y sigue distinguiéndonos a nivel internacional. No resulta tan común que en otras partes del mundo un mandatario pueda tener ese grado de familiaridad, buen trato y cercanía con el resto de los ciudadanos; es algo a preservar y que nos debe llenar de noble orgullo. Sin embargo, en el caso en cuestión, la nota discordante la dio una persona que justo cuando pasaba el Presidente, exclamó a boca de jarro “¡Sos un hijo de puta!” La persona fue detenida inmediatamente e iba a ser puesta a disposición de la justicia; pero intervino el propio Presidente y a su solicitud, fue dejado en libertad. Y no pasó más nada...

¿No pasó nada más? Pienso que sí pasó. Ocurrió algo grave que el Presidente de ese momento dejó pasar por alto, perdonó o restó la trascendencia que tenía; por su gallardía, por su sentido de preservación de la democracia y de las libertades individuales. Consideró en ese momento que se debía tolerar esa injuria o insulto porque se lo habían cometido a él, con nombre y apellido. Y fue magnánimo, generoso, pues actuó sin enfado ni rencor. Pero a mi entender, cometió un error, y fue el de no advertir que en ese momento la ofensa no se le estaba haciendo a su persona en particular, sino a la institución que él representaba: una ofensa a la Presidencia de la República como institución que debe respetarse en todo momento y circunstancia. Al menos podría ser considerada como una falta prevista en el art. 360 del Código Penal, la cual es pasible de una pena de siete a treinta días de prestación de trabajo comunitario. Al no tomar medidas ante el insulto, el Presidente fue clemente frente a una posible ofensa personal, pero ciego o distraído ante una ofensa institucional, tal como la que puede hacerse contra otros símbolos republicanos como son el escudo, la bandera o el himno nacional. 
El primer ejemplo fue uno de incumplimiento de meras normas de educación y convivencia social-familiar. El segundo fue una muestra de irrespeto institucional (además de personal). Mi lectura de las actitudes de quienes tuvieron que sufrir esos desplantes fue de claudicación. Por razones muy comprensibles, pero equivocadas. Por no hacer valer en un caso la autoridad - familiar en un caso e institucional en el otro - dieron pie para que se iniciara un proceso, el del acostumbramiento a no reaccionar ante la falta de respeto. $Y$ una vez que se inicia ese proceso de acostumbrarse ante lo negativo, se inicia un viaje de muy difícil o imposible retorno.

Se supone que las leyes y las normas en general son una manera de regular y controlar conductas. Me refiero a aquellas que son razonablemente justas y razonables, aunque a no todos agraden. Se supone que desde temprana edad se van inculcando este tipo de normas a los niños y jóvenes para que se vayan acostumbrando a respetarlas, asumirlas, internalizarlas y vivirlas como algo habitual que ayuda a la convivencia humana. Desde pedir las cosas por favor, dar gracias, tener horarios para despertarse, comer e irse a dormir, hasta otro tipo de normas más complejas y posteriores, todas ellas cumplen la finalidad de ordenar las conductas, hacerlas más armoniosas y llevaderas. Sin ellas la vida humana sería un caos. En general, además, esas normas no son arbitrarias e injustas; sus prescripciones apuntan a que los seres humanos seamos un poco más agradecidos, generosos, serviciales, ordenados en nuestra vida e incluso un poco menos soberbios, pues nos vamos habituando a respetar algo que está por encima de nuestros pequeños o grandes deseos, caprichos y sentimientos. Por eso es también que una mayoría razonable de personas las comprende, acepta y obedece. Esa aceptación y obediencia no es fruto del miedo o de la resignación. En la mayoría absoluta de los casos, es un acatamiento racional y libre, por comprender que favorece y conviene a todos, pues estimula una mayor y mejor convivencia armónica.

Por supuesto, no les gusta a los anárquicos, pues para ellos ese tipo de normas no deberían existir; solo deberían regir las que ellos imponen, colocan y vuelven a quitar a su real antojo y sentir. Lo curioso e irónico es que esos mismos anárquicos y defensores de la anomia no son tan ignorantes y estúpidos como para permitir que sus hijos pequeños hagan lo que se les ocurra y tengan ganas a la hora de irse a dormir, o ver cualquier tipo de programa de televisión o quedar adheridos a cualquier pantalla de teléfono o computadora.... Tienen una conducta significativamente similar a los que elogian el sistema de educación pública, pero envían a sus propios hijos - si pueden a escuelas de gestión privada. Se parecen también con aquellos que proclaman loas y apoyan abiertamente en cuanta ocasión se les presente a las dictaduras que existen en Cuba, Nicaragua o Venezuela, pero a la hora de viajar ellos o enviar a sus hijos a estudiar fuera del país, eligen otros destinos... En otros aspectos, se parecen a algunos de los que reclaman a viva voz que no se maltrate más a los perros y otros animales; acompañan a los bovinos en velas nocturnas previas a ser sacrificados y muertos en los frigoríficos (de una forma muy brutal y salvaje, es justo decirlo), o están preocupadísimos por la extinción de algunas especies como las ballenas, rinocerontes y osos koalas. Pero, por otro lado, no les inquieta ni se afligen por el destino de millones de seres humanos concebidos sin nacer, que también mueren de forma brutal, cortados y despedazados, disueltos por ingredientes químicos o son succionados como basura; o qué está sucediendo con los derechos humanos de millones de seres humanos en países que sufren opresiones y tiranías de diversos tipos. Coherencia, ¿a dónde te fuiste? 
Volvamos a las normas y a la autoridad; su relación es lógica e inevitable. La autoridad, sea familiar, empresarial o estatal, es la que las establece; y esas normas en general se respetan y acatan no sólo porque son consideradas como provenientes de la autoridad, sino además por ser ellas mismas un reflejo de esa autoridad. Siempre es conveniente recordar la diferencia entre poder y autoridad que ya los romanos distinguían con meridiana claridad. El poder a secas supone fuerza pura, cuando no violencia. Se impone por esa misma fuerza y no hay margen para discutirlo. La autoridad no se impone; se conquista o se va infiltrando por el buen ejemplo, se destila y va impregnando las conductas y actitudes ajenas por osmosis; no es necesario recurrir a otro medio para su aceptación que no sea el buen ejemplo, los altos y profundos conocimientos sobre el tema en cuestión, así como la experiencia adquirida durante cierto tiempo y la probidad. También es clave el haber vivido e internalizado antes lo que se quiere transmitir después. Por eso mismo, no respetar ese tipo de autoridad es en cierta manera ejercer violencia, atacar y vulnerar lo que razonablemente se entendería como respetable. Hay que reconocer que saber congeniar y ejercer el poder junto con la autoridad no es sencillo ni es para cualquiera; es fruto de la prudencia y de la sabiduría y ello no se consigue ni se adquiere en cualquier tiempo o lugar.

Autores como Girgis, Anderson y George consideran que las leyes y las normas en general tienden a educar y a diseñar creencias, costumbres y creencias. Ello supone a su vez, que esas creencias, costumbres y creencias van generando conductas cada vez más habituales. Por último, esas creencias y conductas afectan a los intereses humanos, al bienestar en general y al bien común de los diferentes grupos humanos (Girgis, Anderson \& George, 2012, pp. 56 y ss.). Como ya expresamos, no comparto la idea que las leyes y normas son únicamente el resultado de las costumbres y creencias anteriormente asimiladas y vividas por un grupo social; en muchas ocasiones, son las nuevas leyes y normas las que van rediseñando esas creencias y costumbres. El proceso que recoge lo ya internalizado en una sociedad y que educa a ese mismo grupo humano no es unidireccional, sino que opera en ambos sentidos; es una ida y vuelta que se retroalimenta continuamente. Esa tarea receptora y emisora es muchas veces recíproca y va generando un acostumbramiento en las sociedades que puede, según los casos y circunstancias, ser positivo o negativo. En tal sentido, dependerá mucho de los valores que estén priorizados por ese grupo social en determinado momento histórico, cómo la escala de esos valores puede irse modificando y alterando a lo largo de la historia. También incidirá la manera en que ese grupo social comprende e interpreta a esos valores según las épocas; cómo interpreta y valora la libertad, la igualdad, la justicia o el respeto a la vida misma.

Por último, no debemos olvidar el rol que cumplen los liderazgos, positivos o negativos, a la hora de influir en la cultura o medio en que están insertos. Pues esos líderes que marcan rumbos, son los que mediante las palabras o los ejemplos persuasivos señalan y orientan cómo interpretar y sentir valores tales como libertad, igualdad o justicia. A veces lo hacen con la ayuda de la fuerza bruta y el miedo, otras con apoyo de los medios de comunicación o mediante un eficaz empleo de las redes sociales; muy claramente lo entendió George Orwell cuando en su famosa 1984 le hacía decir a los gobernantes de -turno que "La guerra es la paz", o que "... Si el líder dice de tal evento esto no ocurrió, pues no ocurrió. Si dice que dos y dos son cinco, pues dos y dos son cinco. Esta perspectiva me preocupa más que las bombas..." (Orwell, 1949). El nazismo también lo entendió muy bien cuando a la entrada de los campos de concentración colocaba la frase "el trabajo os hace libres...". 
A fuerza de repetir y repetir, muchas de esas frases se incorporaban en el intelecto y los sentimientos de la gente común, hasta que pasaban a ser como una parte de su propio ser. Y si hubiera dudas al respecto, recuerden a Joseph Goebbels.

¿Cuánto tiempo creen ustedes que puede llevarle a un grupo social pequeño o grande acostumbrarse a un cambio de normas como por ejemplo, a no almorzar y cenar a cierta hora, a no lavarse las manos y dientes antes y luego de esos espacios, a no bañarse con regularidad, o a aspectos más profundos como son la violencia verbal o física, el insulto a la hora de discutir, la falta de respeto entre los que conviven, o la humillación pública en vez de la corrección en privado en los lugares de trabajo? Me animo a decir que no son años, sino unos pocos meses o semanas. Ocurre algo análogo a tener que vivir al lado de un basural maloliente e insalubre. Al cabo de corto tiempo, quienes tienen la mala suerte de tener que habitar allí, van a incorporar ese mal olor y se acostumbrarán a convivir con esos desagradables aromas.

Todos esos "nuevos hábitos" pasarán a ser "normales" al cabo de muy poco tiempo. El ser humano es un ser que se habitúa y acostumbra a todo; a lo positivo y a lo negativo, y en corto tiempo. Entonces se "normalizará" lo que hasta poco tiempo antes era considerado anormal, irregular o contrario a las costumbres vigentes.

La pregunta acuciante que surge es si todas esas normalizaciones son positivas y convenientes; si perfeccionan o empobrecen la convivencia humana; si enriquecen o desmejoran a las personas. No es lo mismo que antes a las personas e incluso a los familiares mayores se les tratara siempre de "usted" y ahora el tuteo pase a ser algo cotidiano, incluso entre personas que se conocen y tratan por primera vez; otra muy diferente es que lo que antes se consideraba una muestra de cortesía y deferencia hacia las mujeres - como puede ser dejarlas pasar antes que el hombre al entrar o salir de una puerta, o ponerse de pie y saludar cuando una persona mayor entra en un lugar - pase a ser considerado actualmente como una muestra de machismo estúpido y agresivo o reflejo de una excesiva y blanda educación burguesa, conservadora y retrógrada.

Como tantas otras expresiones, resulta que hoy en día, la palabra "conservador" ha pasado a integrar el elenco de términos despectivos que procuran ensuciar y disminuir a las personas mencionadas como tales. Si a una persona la tildan de conservadora eso es sinónimo de varias cosas a la vez: derechista, burgués, neo liberal, capitalista opresor, imperialista y probablemente fanático y religioso. Como si todos esos epítetos fueran sinónimos. Como si no existieran fanáticos que no son religiosos o religiosos que no son fanáticos... Para muestra de simple botón, alcanza con ver las conductas y reacciones de algunos hinchas de equipos deportivos en muchas partes del mundo.

En lo que a la expresión conservador refiere, pienso que hay aspectos de la vida cotidiana que no solamente es conveniente, sino muy necesario conservar. Por la simple razón de ser señales. Signos que indican rumbos y marcan límites. Los límites precisamente marcan hasta dónde se puede llegar. Limitan, pero precisamente por eso, encausan, conducen, orientan. Un río fuera de cauce, que se salió de sus límites es un río desbordado que - según una expresión popular - "se desmadró" esto es, "se salió de madre, de límites". Un río fuera de cauce, que se sale de límites genera caos y daños. Con algunas normas, costumbres y tradiciones sucede algo similar; si se socavan, ignoran o eliminan, habrá daños sociales y deterioro en la convivencia humana. Por eso es no sólo 
conveniente, sino imprescindible preservarlas. Por ejemplo, si resulta ser conservador mantener la tradición de los almuerzos familiares de los sábados o domingos; si se entiende que es de "tradicionalistas" fomentar los partidos de truco con amigos cerca del parrillero mientras se hace el asado; si respetar a los mayores y ponerse de pie cuando ingresan a una sala está considerado obsoleto anticuado y conservador; si a la hora de discutir ideas ahora hay que aceptar como normal despreciar, insultar o burlarse de quien piensa diferente, pues con tranquilidad y orgullo seguiré aceptando el mote de conservador. Si por tradicionalista y conservador se entiende que hay que seguir respetando otros puntos de vista y discutirlos con serenidad y argumentos fuertes pero sin descalificar, injuriar ni mofarse de los contrarios; si por tradicionalista y conservador se interpreta que hay que continuar tratando a los demás, en particular a los más jóvenes y a los más ancianos, como fines en sí mismos y no como objetos descartables que se usan y luego se tiran como si fueran material desechable; si por tradicionalista y conservador se tilda a quienes pretenden mantener unas reglas mínimas de buena educación, que apuntan a respetar ciertas normas en la forma de hablar y de escribir, que le dan a la estética y la belleza en todas sus manifestaciones el lugar que le corresponde, entonces bienvenido sea el mote de tradicionalista y conservador.

Y si continúan existiendo normas, costumbres y tradiciones que marcan los límites de esa educación y convivencia humana, también bienvenidas sean. En tal sentido, no comparto la idea de Daniel Goldman, citado por Fernando Savater (2006), cuando sostiene en una de las obras de este último, que:

la educación es el arma de la censura por excelencia. Es la forma que tiene la sociedad para indicarte lo que no debes hacer. En hebreo la palabra educación se dice jinuj, que puede implicar educación o, en su extremo, ahogo, sofoco... (p. 27).

No discuto que en algunos momentos de la historia y en algunas culturas y regiones la educación pudiera asimilarse a lo que Savater describe a través del entrevistado Goldman. Pero esas excepciones no han sido la regla. La educación bien entendida y aplicada por las familias en general y los expertos en la educación en particular, (en ese orden jerárquico y no a la inversa), ha supuesto directivas y orientaciones, reglas y normativas, palabras, frases y ejemplos reales que no han sofocado, sino ayudado a los educandos a conformar sus propios destinos, a construir sus propias libertades con responsabilidad, a volver a comenzar a partir de los propios errores, a ser exigentes sin dejar de ser comprensivos; a entender que la sana exigencia forma parta ineludible de querer bien y formar mejor a los exigidos. No es ni por asomo un arma para la censura, sino una herramienta que - bien empleada - construye una mejor convivencia y ayuda a promover el bien común de una sociedad concreta en un momento histórico dado.

Esas reglas y normas tienen un objetivo que las trasciende. No son fines en sí mismos, sino medios, instrumentos para construir y apuntalar una palabra y una actitud que en nuestros días se utiliza poco y se vive menos: la disciplina. Es difícil encontrarle a la disciplina un sinónimo o término similar. En general se entiende la disciplina como " $e l$ conjunto de reglas de comportamiento para mantener el orden y la subordinación entre los miembros de un cuerpo o de una colectividad en una profesión o en un determinado grupo social." También se la considera como "el conjunto de reglas o normas cuyo cumplimiento de manera constante 
conduce a cierto resultado..." Esto incluye la sanción por su inobservancia. Finalmente, y es lo que más desearía resaltar en esta instancia, la disciplina, según el Diccionario de la Real Academia Española, puede entenderse como "el arte, la facultad o ciencia de instruir y educar a las personas". La educación no es simple instrucción; apunta a algo más alto y completo en la persona humana. No implica una mera transmisión de conocimientos y técnicas. Su finalidad debe ser más amplia y ambiciosa: la formación integral o global del individuo en sus diversas y complementarias dimensiones: intelectual, físico-corporal o deportiva, ética, afectiva, estética y espiritual. Todo ello combinado y acrecentado es lo que "cultiva" al hombre y a la vez lo hace más culto, más íntegro y completo. No se trata entonces de obedecer esas normas o reglas por el simple hecho de que existen. No es cuestión de promover una disciplina y obediencia ciega porque debe obedecerse cualquier disposición impuesta. Se trata de alentar una obediencia inteligente, previsora y responsable, pues en la medida que se logre, irá forjando y plasmando una mejor manera de comprender la libertad y de promover una coexistencia humana más armoniosa.

En última instancia, lo más importante de la existencia de las normas y reglas, sea del tipo que sean, es que, si son razonables, justas y no arbitrarias, induzcan a los receptores de las mismas a generar este criterio: "es preferible cumplirlas, pues no hacerlo es a la corta o a la larga peor y más caro...". Esto es educar armonizando la disciplina y la libertad responsable.

Vamos a desarrollar un poco más esta sinergia y armonización entre la libertad y el cumplimiento de ciertas normas. Como ya fue dicho, nos estamos refiriendo a aquellas que son consideradas razonables y dotadas de cierto grado de sensatez y aceptadas por el sentido común de la comunidad a la que están dirigidas. En segundo lugar, habrá que distinguir entre las que son jurídicas, las éticas o morales y las reglas sociales. Es claro que la coercibilidad varía según sean unas u otras. Sin perjuicio de ello, es interesante constatar que, en muchas ocasiones, se da un acatamiento mayor en el caso de las sociales que en el caso de las jurídicas; me refiero a casos en los que para algunas personas les resulta menos gravoso pagar una multa o recibir la sanción que impone una ley, antes que recibir la censura social del escrache en las redes, o el retiro del saludo personal en ciertos lugares públicos.

Un claro y actual ejemplo de estas distinciones es el de la vacunación en esta época de pandemia. Algunos países la impusieron en forma obligatoria por ley, mientras que otros como el nuestro, no. En este país se apeló a la denominada libertad responsable y quedó en los habitantes la opción de elegir entre vacunarse o no hacerlo. En consecuencia, desde el momento que se respetó la libertad de cada uno, esa misma libertad no debería restringirse a posteriori, sancionando a quienes optaron por no vacunarse con medidas que puedan afectar sus derechos. Algunos podrán sostener que esto es muy discutible y que la libertad de unos termina cuando afecta la libertad de otros; es cierto, y ello produce serios problemas de armonización de derechos y valores que pueden chocar entre sí, como son la libertad, la igualdad, la seguridad y la salud pública. Problemas o antinomias al decir de Gustavo Radbruch - que son graves y viejos como la historia de la convivencia humana. No se trata de pretender resolverlos ahora, sino al menos dejarlos planteados con una reflexión: es muy fácil proclamar y defender los derechos, valores y principios fundamentales en épocas tranquilas; la clave es mantener esa postura con coherencia en las crisis y momentos difíciles. No hay ni habrá recetas para decidir 
cuál de ellos debe primar sobre los otros; quizás lo más importante a tener en cuenta es que por encima de todos ellos debería sobrevolar la vida y dignidad de todo y cada ser humano, sin distinción de ningún tipo.

En materia de conflicto de derechos y valores, la jerarquización y escala de ellos ha variado a lo largo de la historia a medida que la educación y el sentido de empatía hacia los demás se fue enriqueciendo y acrecentando. También esa variación puede darse en un mismo individuo en el transcurso de su vida, larga o corta, por múltiples motivos. Robert Spaemann (1995) nos ilustra esto citando una situación que fue muy debatida y sensibilizó a nuestra población unos años atrás:

...Si por ejemplo colisionan los derechos de fumadores y no fumadores que están en una misma habitación, y el conflicto se resuelve a favor de los no fumadores, eso no ocurre porque éstos sean mejores personas - cosa que con todo derecho discutirían los fumadores -, sino porque el valor que invocan los no fumadores tiene preferencia sobre el placer de fumar. Y el fumador se somete incluso a este juicio, aun cuando le desagrade, por la sencilla razón de que comprende que es así. Quien está dispuesto a aceptar esa manera de entender el valor que se opone a su inmediata satisfacción, es capaz de lo que se llama una acción valiosa. La capacidad de conocer valores crece si uno está dispuesto a someterse a ellos, y disminuye cuando no se da esa disposición... (p. 50).

Esta capacidad de reconocer y aceptar unos derechos y valores por encima de gustos e intereses personales, no es nada fácil de adquirir, como lo muestra el mismo caso de conflictos y tensiones que se dio durante cierto tiempo en nuestro país cuando la libertad de fumar en cualquier lado y oportunidad se vio restringida. Hubo protestas, resistencia y rebelión durante meses por parte de quienes se consideraron perjudicados; fue el rigor de las medidas, la inquebrantable decisión de las autoridades en mantenerlas, pero principalmente, lo razonable y sensato de las mismas, la que fue modificando esa rebeldía inicial hasta transformarla en una pacífica y razonada aceptación; hasta que llegó el natural y lógico acostumbramiento. Un irse habituando más rápida o lentamente a reconocer y aceptar que los gustos y necesidades de unos tienen que a veces ceder ante los gustos y necesidades de otros, sobre todo si lo que está en juego es algo que a todos involucra: el valor y principio de la salud personal y pública. En la actualidad, muy pocos o nadie discute que las medidas y disposiciones adoptadas en aquel momento con relación a fumadores y no fumadores fueron adecuadas y justas. Y es que, retornando a Spaemann (1995), “...Llamamos justo a aquel que, en los conflictos de intereses, examina de qué intereses se trata y está dispuesto a pasar por alto de quién son los intereses que están en liza..." (pp. 60-61).

Volvamos a la libertad y su relación con la sujeción a las normas y reglas. Comencemos por citar nada menos que a un enamorado de la libertad y típico representante del pensamiento denominado romántico, cuando la emoción y los sentimientos fueron adquiriendo un rol cada vez más protagónico: Jean Jacques Rousseau. Digo nada menos, porque es de los pocos momentos en los que coincido con su manera de pensar. El locuaz y convincente ginebrino, con sus loas a la libertad, los buenos sentimientos del salvaje original y la apoteosis de la voluntad general, sedujo, en todo el término de la palabra, a más de un libre-pensador y sobre todo a más de una integrante de los salones 
culturales de su época, sembrando las semillas que germinarían poco tiempo después en una cruenta y caótica revolución, que, bajo el lema de Libertad, Igualdad y Fraternidad, generó un autoritarismo despótico, primero con pseudo-asambleas y luego con Napoleón Bonaparte; esa revolución tuvo poco respeto por la igualdad de derechos y deberes, y fue cualquier cosa menos fraterna con los que pensaban distinto...

Volvamos a Rousseau:

Podría pensarse que este pensador no estaría muy inclinado a ese tipo de sujeciones por ir en contra de su pasión por la libertad; sin embargo, leemos en su Contrato Social que si bien por un lado

...renunciar a la libertad es renunciar a la cualidad de los hombres, a los derechos de humanidad e incluso a los deberes. No hay compensación posible para quien renuncia a todo. Tal renuncia es incompatible con la naturaleza del hombre, e implica arrebatar toda moralidad a las acciones el arrebatar la libertad a la voluntad... (Rousseau, 1986, p.13),

más adelante va a sostener que

es preciso distinguir la libertad natural, que no tiene más límite que las fuerzas del individuo, de la libertad civil, que está limitada por la voluntad general, y la posesión, que no es sino el efecto de la fuerza o el derecho del primer ocupante, de la propiedad, que no puede fundarse sino sobre un título posesivo.(...) Se podría agregar a lo adquirido por el estado civil, la libertad moral, la única que verdaderamente hace al hombre dueño de sí mismo, porque el impulso exclusivo del apetito es esclavitud, y la obediencia a la ley que se ha prescrito es la libertad... (Rousseau, 1986, p. 23)

Es interesante notar que un autor como Rousseau, tan característicamente amante de la libertad, no se olvidaba de sugerir los límites que hay que trazarle, para evitar que sus excesos incontrolados se transformen en esclavitud. Ya entonces se recordaba el freno de la responsabilidad para no proclamar y vivir una libertad ilimitada, pues hay deberes que deben cumplirse como forma de preservar y apuntalar esa misma libertad. En otras palabras, Rousseau en teoría al menos, intuyó que una libertad sin frenos, límites ni responsabilidad personal, puede dar origen a las peores dependencias y sumisiones.

Más recientemente, Álvaro d’Ors (2001), luego de sostener que en su opinión el derecho llamado natural no consiste en derechos subjetivos sino en deberes, cuando se refiere a la relación entre responsabilidad y libertad, afirma que la

...libertad esencial no consiste siempre en poder elegir una conducta, sino en poder optar por ella. La diferencia entre elegir y optar está en que la elección presupone una multiplicidad de posibilidades, y la opción, en cambio, consiste en la aceptación de una, incluso única, posibilidad concreta. Así, el hombre puede elegir entre contraer matrimonio o no, pues las posibilidades son sólo estas dos; pero si elige el matrimonio, no elige la persona del cónyuge, pues no puede comparar todos los posibles cónyuges, sino que opta por uno determinado sin consideración de los otros posibles. Los condicionamientos de la vida humana suelen impedir una elección absoluta y reducir las posibilidades de comparación y preferencia, hasta el punto de que la libertad quede 
a veces reducida, como digo, a la opción o no de una única posibilidad; así ocurre al que va a morir, cuya libertad se reduce a optar, es decir, a aceptar la muerte o no aceptarla, aunque ésta sea inevitable.(...) Es un error, pues, negar la libertad humana por la reducción de las conductas elegibles, pues la libertad no consiste en poder elegir, sino en poder optar, y no hay fuerza coactiva alguna que prive al hombre de esa libertad de opción... (pp. 34-35).

\section{A consecuencia de ello, d’Ors (2001) convoca a la responsabilidad como}

la necesidad de aceptar los efectos de las propias opciones. En este sentido, la responsabilidad lleva al hombre a perder parte de su libertad, pues al optar una determinada conducta queda moralmente vinculado a sufrir los efectos de la conducta optada (...) El hombre es, por naturaleza, un ser responsable, y su libertad está en función de su responsabilidad; la responsabilidad personal es un dato objetivo, y la libertad es el presupuesto subjetivo de la responsabilidad. Podemos decir, pues, que el hombre es libre porque es responsable, no que es responsable porque es libre: lo esencial es la responsabilidad y la libertad, un requisito de la responsabilidad... (p. 36).

Lo desafiante y original de este planteo de Álvaro d'Ors es que propone lo que podríamos llamar un giro copernicano a lo que habitualmente se entiende como relación entre libertad y responsabilidad; no se trata de ver tanto a la responsabilidad como consecuencia de la libertad, sino de ver a la libertad como presupuesto y fundamento de la responsabilidad. Esto permite atenuar el énfasis en una libertad entendida como fin en sí mismo y como atributo sin límite alguno. Es una cualidad del ser humano que éste deberá administrar con cuidado para no dañarla, disminuirla o perderla definitivamente cuando se antepone a la responsabilidad. El planteo de este filósofo ayuda también a comprender que el ser humano no tiene por su propia naturaleza exclusivamente derechos sino deberes, y que invocar solamente aquellos sin tener en cuenta a estos, es la mejor receta para promover convivencias inconsistentes e insostenibles, por caóticas, incoherentes y de corta duración.

Hay muchas personas que rechazan las reglas y normas por ignorancia pura y simple. Pero existen muchas también que las niegan y combaten por tozudez, o por ánimo simple y puro de desafiar a la autoridad que las pretende inculcar. Esto es viejo como el mundo. Sería interesante hacer una encuesta lo más amplia posible para intentar averiguar si esa misma gente que no quiere respetar algunas normas elementales que apuntan a la educación y el cuidado de todos en salubridad pública, o a las costumbres de una sana convivencia ciudadana en la política, en la empresa, el trabajo o los espectáculos públicos, si esa misma gente estaría dispuesta a romper otro tipo de reglas y normas para aceptar que de aquí en adelante, al fútbol se pudiese jugar con una pelota ovalada y sin árbitros que determinen cuándo hay faltas o jugadas anti-deportivas; que a la hora de tener una enfermedad del tipo que sea, entendieran razonable acudir a un mecánico antes que a un médico, o a la hora de construir un edificio, que el mismo sea diseñado y ejecutado por un abogado. También sería interesante preguntarles si aceptarían ir a un restaurante y a la hora de pedir un pollo para comer, le traigan un gato con el mensaje de que últimamente los pollos son un nuevo tipo de ave cuadrúpeda, sin alas ni plumaje. 
Por último, siempre podemos encontrar a los que sostienen que - efectivamente hubo incumplimientos, pero que a) en realidad los incumplimientos los hicimos todos o b) que venían gestándose desde mucho tiempo atrás y que por tanto ellos no hicieron otra cosa que seguir la corriente. En un artículo muy lúcido y certero Andrés Danza hace referencia a estos dos últimos argumentos que muchos utilizan para justificar y excusar lo injustificable e inexcusable. Bajo el título "No fuimos todos", Danza nos muestra con meridiana claridad que el primer pseudo-argumento (o argumento débil al decir de Perelman) sólo pretende esconder el refugio en lo colectivo o la recurrente despersonalización de responsabilidades, vieja como la historia del ser humano, que tantas personas y organizaciones pretenden invocar para diluir sus responsabilidades. En palabras de Danza (2021),

...es como escudarse en aquel fuimos todos de la adolescencia. Y no, no fuimos todos. Hay muchos otros que pagan sus impuestos, que construyen en regla y que, si eso no ocurre, son perseguidos y multados. A ellos ni se les ocurre hacerlo de otra manera. No necesariamente por convicción, sino por temor a las consecuencias... (p. 2).

Lo que indirectamente está resaltando Danza es que existen muchas personas que no le rinden culto a la maldita viveza criolla que tanto mal le hace a nuestra sociedad. En cuanto al segundo argumento, se derrumba y viene abajo por su propia debilidad: sostener y defender que hay que seguir haciendo mal las cosas e incumplir porque otros antes también lo hicieron, es reflejar una pervertida obsecuencia. Llamarle coherencia a la persistencia en el error y el engaño es la mejor receta para seguir pegándose tiros en el propio pie hasta que convenga amputarlo. De nuevo Danza (2021) nos ilustra:

... Lo que estaba mal antes y fue criticado, está mal ahora. No importa quién esté a cargo en el poder. Ese argumento de como ellos lo hicieron, nosotros podemos, es por los menos, descalificador. Las comparaciones pueden ser útiles, pero para mostrar algo mejor, no lo mismo... (p. 2).

Me permito añadir que este acostumbramiento a las maniobras arteras y corruptas procedentes de la persona, la empresa, el partido o la organización que sea - es el camino más rápido y directo para el derrumbamiento político, ético, económico y cultural de una sociedad. Basta con examinar y repasar la historia, desde la Roma Imperial hasta nuestros días.

Ocurre a menudo que a quienes no les gusta que le den gato por liebre, o quienes exhortan a que se respeten las normas de la naturaleza, tanto exterior, que se encuentra fuera del control humano, como la interna del ser humano, que sí es más controlable si educa su razón y su voluntad, son inmediatamente tachados de intolerantes y retrógrados.

En esta época que nos toca vivir, dar gato por liebre (o por pollo, según los gustos) se ha vuelto una costumbre cada vez más común. Se hace por medio de juegos de palabras que no son otra cosa que nuevos eufemismos. Con ello se pretende transformar la venganza en justicia, las desobediencias irracionales en conquistas de la libertad; las necesidades o gustos personales - en ocasiones anormales - y a algunos caprichos, en derechos humanos. 
Lo preocupante es que en variadas ocasiones esto se logra, gracias a un deterioro educativo y cultural extendido que ha sustituido el esfuerzo por la cultura y el arte a cambio del entretenimiento y diversión barata, directa y eficaz. Que ha reemplazado la lectura de los autores clásicos o contemporáneos, lo cual a veces lleva mucho tiempo, a cambio de horas y horas de "atornillamiento" a series televisivas con guiones tan eficaces como prolongables cual un elástico hasta el infinito.

El problema no es que el mundo haya cambiado y que ahora existan las nuevas pantallas y la nueva tecnología. El problema surge cuando esas novedades reemplazan total y absolutamente a lo anterior, y no permiten una combinación adecuada y armónica entre lo nuevo y lo viejo. Ese es el momento en que las personas pueden comenzar a perder su individualidad, su originalidad, su propio ser, para entregarse (zambullirse a veces) en una masificación que las entretiene, narcotiza y deshumaniza.

Un enfoque moral y ético de las normas y la autoridad supone tener una perspectiva realista, un punto de vista que acepte razonablemente armonizar lo individual con lo universal, la imparcialidad y el interés propio. En ese sentido, comparto la visión de Martin Rhonheimer (2020) cuando afirma:

...Ciertamente, aquí no se afirmará de ninguna manera, que la perspectiva de la moral no sea la de un punto de vista universal o superior que corrige el puro interés propio. Lo que se discute es únicamente esa pretendida contraposición entre interés personal y moral, o, lo que es lo mismo, un concepto de la moral como limitación de lo que va en nuestro interés personal. La perspectiva de la moral tal y como vamos a entenderla aquí, es el punto de vista del hombre como unidad corporal-espiritual y como sujeto actuante, equipado con impulsos, afectos y emociones; de instintos débiles pero al mismo tiempo capacitado para trascender su propia centralidad mediante el intelecto y la voluntad y abrirse así a otros; libre, y a la vez siempre expuesto a malograr su libertad: por un lado dueño de sus actos, pero por otro siempre en peligro de convertirse en esclavo de ellos. Desde este punto de vista, la dicotomía interés propio/moral carece de sentido. En efecto, aquí la moral está precisamente al servicio del interés en que se pueda decir que propia existencia es una existencia lograda, del interés por la vida buena. (...) "el interés de quienes en cada caso sean los otros, o de la colectividad, por su bien y por lo bueno para ellos se puede entender ahora también como propio interés, dado que - en tanto el actor trata de ser coherente - parece imposible reconocer y perseguir en la práctica algo de verdad bueno para mí si no lo reconozco por principio como bueno para los demás, y si por tanto no tengo también un interés personal en que ellos participen de ese bien. La relevancia de la moral y de su pretensión de verdad para la persecución de mi interés personal garantiza precisamente la universalidad de esa pretensión, la comunidad de intereses y con ella, una imbricación fundamental aunque no necesariamente sin fisuras - de interés propio y moral. Ciertamente, esto no quiere decir que las exigencias morales o los juicios prácticos sean esencialmente universales o universalizables. Muy al contrario, son particulares, vinculados a la situación y, como dice Aristóteles, siempre cambiantes. (...) La verdadera dicotomía propia de la perspectiva de la moral, es por tanto, la que existe ante la razón práctica entre la apariencia meramente subjetiva del bien y la verdad de ese aparecer del bien... (pp. 19-20). 
En el lenguaje de los negocios últimamente se utiliza la expresión "ethics is good business" (la ética es buen negocio) para reflejar en términos concretos lo que Rhonheimer expresa de manera mucho más académica y filosófica: no se trata de antagonizar la moral con el interés individual, sino de captar y comprender la ventaja, no solo personal y espiritual, sino también económica, de conocer, internalizar y practicar (vivir) una ética objetiva y universal. El viejo refrán de no hacerle a los demás lo que no nos gusta que nos hagan a nosotros o, por la positiva, de hacerle a los otros lo que nos gustaría que nos hagan mantiene plena vigencia. En su comprensión y praxis radica la manera más efectiva y eficiente de seguir construyendo una convivencia más armónica, más respetuosa, empática y fraterna para con ello, alcanzar dentro de lo que es razonable y posible en esta tierra, un mayor grado de felicidad.

¿Será posible tener que volver a encontrarnos con el Mundo Feliz que describió Aldous Huxley para darnos cuenta que no es tan feliz y que - quizás - sea demasiado tarde?

Comparto la idea de que todos cosecharemos lo que sembramos; ni más ni menos. Pero al igual que en la agricultura, algunos siembran mejores semillas en tierras preferibles y luego cosechan mejor que otros. Todo dependerá de cada uno. Al fin de cuentas, como decía Artigas, la autoridad emana de nosotros.

\section{Referencias bibliográficas}

Danza, A. (2021) No fuimos todos. Búsqueda - Año XLIX N 2.135. Montevideo 12 al 18 agosto.

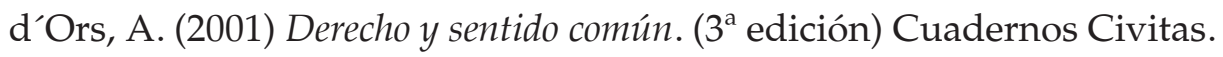

Girgis, S. Anderson, R. \& George, R. (2012). What is marriage? London: Encounter Books - New York.

Orwell, G. (1949) 1984. Bogotá: Debolsillo.

Rhonheimer, M. (2000) La perspectiva de la moral. Fundamentos de la ética filosófica. España: Ediciones RIALP.

Rousseau, J.J. (1986) El Contrato Social. Servicio de documentación de Historia de las Ideas. Serie Antología. Fundación de Cultura Universitaria.

Savater, F. (2007) Los siete pecados capitales. Buenos Aires: Editorial Sudamericana.

Spaemann, R. (1995) Ética. Cuestiones Fundamentales. (4ª edición) España: EUNSA 